\title{
CRÓNICA CONSTITUCIONAL DEL AÑO 2008
}

MIGUEL ÁNGEL PRESNO LINERA 



\title{
CRÓNICA CONSTITUCIONAL DEL AÑO 2008
}

\author{
POR \\ MIUEL ÁNGEL PRESNO LINERA \\ Profesor Titular de Derecho Constitucional \\ Universidad de Oviedo \\ presno@uniovi.es \\ http://www.uniovi.es/constitucional/miemb/presno.htm \\ blog jurídico: http://presnolinera.wordpress.com
}

En esta Crónica se realiza una presentación de carácter temático y no exclusivamente cronológica, con el propósito de presentar una panóramica más completa de los sucesos relatados. Como en años anteriores, los grandes bloques temáticos se refieren a la Unión Europea y las relaciones internacionales; los partidos políticos y los procesos electorales y de referéndum; los órganos constitucionales y autonómicos; la organización territorial del Estado, y los derechos, deberes y libertades de los ciudadanos.

\section{UNIÓN EUROPEA Y RELACIONES INTERNACIONALES}

En el ámbito jurisprudencial, y a propósito de los litigios en los que ha sido parte el Estado español y que tienen relación con los asuntos tratados en esta crónica, cabe recordar las siguientes sentencias ${ }^{1}$ :

${ }^{1}$ Disponibles en http://curia.eu.int/es/content/juris/index rep.htm 
1) la sentencia del Tribunal de Justicia (Sala Quinta), de 31 de enero de 2008, declaró:

que el Reino de España ha incumplido las obligaciones que le incumben en virtud de la Directiva 2001/84/CE del Parlamento Europeo y del Consejo, de 27 de septiembre de 2001, relativa al derecho de participación en beneficio del autor de una obra de arte original, al no haber adoptado, dentro del plazo señalado, todas las disposiciones legales, reglamentarias y administrativas necesarias para ajustarse a dicha Directiva.

2) La sentencia del Tribunal de Justicia (Sala Octava), de 14 de febrero, declaró:

que el Reino de España ha incumplido las obligaciones que le incumben en virtud de la Directiva 2003/110/CE del Consejo, de 25 de noviembre de 2003, sobre la asistencia en casos de tránsito a efectos de repatriación o alejamiento por vía aérea, al no haber adoptado las disposiciones legales, reglamentarias y administrativas necesarias para atenerse a dicha Directiva. claró:

3) La sentencia del Tribunal de Justicia (Sala Tercera), de 14 de febrero, de-

que el Reino de España ha incumplido las obligaciones que le incumben en virtud del artículo $56 \mathrm{CE}$ al mantener en vigor medidas como las previstas en la Disposición Adicional vigésima séptima de la Ley 55/1999, de 29 de diciembre, de Medidas fiscales, administrativas y del orden social, en la redacción dada a la misma por el artículo 94 de la Ley 62/2003, de 30 de diciembre, que limitan los derechos de voto correspondientes a las acciones poseídas por las entidades públicas en las empresas españolas que operen en el sector energético.

4) La sentencia del Tribunal de Justicia (Sala Tercera), de 6 de marzo, declaró

que el Reino de España, al no haber retirado:

- las condiciones primera a sexta, octava y decimoséptima impuestas por la resolución de la Comisión Nacional de la Energía, declaradas incompatibles con el Derecho comunitario por el artículo 1 de la decisión de la Comisión de 26 de septiembre de 2006 [Asunto n COMP/M.4197 E.ON/Endesa C(2006) 4279 final], y

- las condiciones primera, décima, undécima y decimoquinta modificadas, impuestas por la resolución del Ministro de Industria, Turismo y Comercio, declaradas incompatibles con el Derecho comunitario por el artículo 1 de la decisión de la Comisión de 20 de diciembre de 2006 [Asunto $n^{\circ}$ COMP/M.4197 -E.ON/Endesa- C(2006) 7039 final], dentro de los plazos señalados, 
— ha incumplido las obligaciones que le incumben con arreglo al artículo 2 de cada una de estas decisiones. claró:

5) La sentencia del Tribunal de Justicia (Sala Tercera), de 13 de marzo, de-

que el Reino de España ha incumplido las obligaciones que le incumben en virtud de los artículos $43 \mathrm{CE}$ y $49 \mathrm{CE}$, relativos a la libertad de establecimiento y a la libre prestación de servicios, y de los artículos correspondientes del Acuerdo sobre el Espacio Económico Europeo, de 2 de mayo de 1992, a saber, los artículos 31 y 36 de este Acuerdo, al mantener en vigor un régimen de deducción de los gastos correspondientes a actividades de investigación y desarrollo e innovación tecnológica que es menos favorable para los gastos realizados en el extranjero que para los gastos realizados en España, tal como resulta de lo dispuesto en el artículo 35 de la Ley del Impuesto sobre Sociedades, Texto Refundido aprobado por Real Decreto Legislativo 4/2004, de 5 de marzo. claró:

6) La sentencia del Tribunal de Justicia (Sala Segunda), de 8 de mayo, de-

que el Reino de España ha incumplido las obligaciones que le incumben en virtud de la Directiva 89/48/CEE del Consejo, de 21 de diciembre de 1988, relativa a un sistema general de reconocimiento de los títulos de enseñanza superior que sancionan formaciones profesionales de una duración mínima de tres años, por lo que respecta a la profesión de farmacéutico hospitalario, al no haber adoptado todas las medidas necesarias para adaptar su Derecho interno a lo dispuesto en dicha Directiva.

7) La sentencia del Tribunal de Justicia (Sala Tercera), de 17 de julio, declaró:

que el Reino de España ha incumplido las obligaciones que le incumben en virtud de los artículos $43 \mathrm{CE}$ y $56 \mathrm{CE}$, al haber adoptado las disposiciones del apartado 1, párrafo segundo, de la función decimocuarta de la Comisión $\mathrm{Na}$ cional de Energía que figura en la disposición adicional undécima, tercero 1, de la Ley 34/1998, de 7 de octubre, del sector de hidrocarburos, modificada por el Real Decreto-ley 4/2006, de 24 de febrero de 2006, con el fin de someter a autorización previa de la Comisión Nacional de Energía la adquisición de ciertas participaciones en las empresas que realicen determinadas actividades reguladas del sector de la energía, así como la adquisición de los activos precisos para desarrollar tales actividades. claró:

8) La sentencia del Tribunal de Justicia (Sala Segunda), de 16 de octubre, de-

que el Reino de España ha incumplido las obligaciones que le incumben en virtud de la Directiva 89/48/CEE del Consejo, de 21 de diciembre de 1988, re- 
lativa a un sistema general de reconocimiento de los títulos de enseñanza superior que sancionan formaciones profesionales de una duración mínima de tres años, y de la Directiva 92/51/CEE del Consejo, de 18 de junio de 1992, relativa a un segundo sistema general de reconocimiento de formaciones profesionales, que completa la Directiva 89/48, al no haber adoptado, en lo que respecta a la profesión de controlador de tránsito aéreo, las disposiciones legales, reglamentarias y administrativas necesarias para dar cumplimiento a las citadas Directivas. claró:

9) La sentencia del Tribunal de Justicia (Sala Segunda), de 23 de octubre, de-

que el Reino de España ha incumplido las obligaciones que le incumben en virtud de la Directiva 89/48/CEE del Consejo, de 21 de diciembre de 1988, relativa a un sistema general de reconocimiento de los títulos de enseñanza superior que sancionan formaciones profesionales de una duración mínima de tres años, en su versión modificada por la Directiva 2001/19/CE del Parlamento Europeo y del Consejo, de 14 de mayo de 2001, en particular de su artículo 3,

- al denegar el reconocimiento de las cualificaciones profesionales de ingeniero obtenidas en Italia sobre la base de una formación universitaria impartida únicamente en España, y

- al supeditar la admisión a las pruebas de promoción interna en la función pública de ingenieros en posesión de cualificaciones profesionales obtenidas en otro Estado miembro al reconocimiento académico de dichas cualificaciones.

10) La sentencia del Tribunal de Justicia (Sala Sexta), de 20 de noviembre, declaró:

que el Reino de España ha incumplido las obligaciones que le incumben en virtud del Derecho comunitario y, en particular, del artículo $39 \mathrm{CE}$, al haber mantenido en su legislación la exigencia de la nacionalidad española para ejercer los empleos de capitán y primer oficial en todos los buques de pabellón español distintos de los buques mercantes de arqueo bruto inferior a 100 toneladas, que transporten carga o menos de 100 pasajeros, que operen exclusivamente entre puertos o puntos situados en zonas en que el Reino de España ejerce soberanía, derechos soberanos o jurisdicción.

11) La sentencia del Tribunal de Justicia (Sala Quinta), de 4 de diciembre, declaró:

que el Reino de España ha incumplido las obligaciones que le incumben en virtud de la Directiva 2006/49/CE del Parlamento Europeo y del Consejo, de 14 de junio de 2006, sobre la adecuación del capital de las empresas de inversión y las entidades de crédito (refundición), al no haber adoptado, en el plazo señalado, todas las disposiciones legales, reglamentarias y administrativas necesarias para 
ajustarse a dicha Directiva y, en particular, a sus artículos 17, 22 a 25, 30, 33, 35, $40,41,43,44$ y 50 y a sus anexos I, II y VII.

12) La sentencia del Tribunal de Justicia (Sala Segunda), de 11 de diciembre, declaró:

que el Reino de España ha incumplido las obligaciones que le incumben en virtud de los artículos 5, apartado 1, y 16, apartado 1, de la Directiva 2000/59/CE del Parlamento Europeo y del Consejo, de 27 de noviembre de 2000 , sobre instalaciones portuarias receptoras de desechos generados por buques y residuos de carga, al no haber elaborado, aprobado ni aplicado planes de recepción y manipulación de desechos para todos los puertos españoles.

En lo que tiene que ver con la actividad normativa estatal vinculada a la Unión Europea, hay que hacer mención a la publicación en el BOE de las siguientes Leyes:

1) La Ley Orgánica $1 / 2008$, de 30 de julio, por la que se autoriza la ratificación por España del Tratado de Lisboa, por el que se modifican el Tratado de la Unión Europea y el Tratado Constitutivo de la Comunidad Europea, firmado en la capital portuguesa el 13 de diciembre de 2007 (BOE núm. 184, de 31 de julio de 2008);

2) la Ley Orgánica 2/2008, de 4 de diciembre, de modificación de la Ley Orgánica 6/1985, de 1 de julio, del Poder Judicial, complementaria de la Ley para la ejecución en la Unión Europea de Resoluciones que impongan sanciones pecuniarias (BOE núm. 293, de 5 de diciembre de 2008);

3) la Ley 1/2008, de 4 de diciembre, para la ejecución en la Unión Europea de resoluciones que impongan sanciones pecuniarias (BOE núm. 293, de 5 de diciembre de 2008).

Por su parte, el Tribunal Europeo de Derechos Humanos (TEDH) recibió a lo largo del año 2008393 demandas contra España y condenó al Estado español en dos ocasiones ${ }^{2}$ :

1) En el caso Barrenechea c. España, la sentencia de 22 de julio estimó que se había producido la vulneración del artículo 6 del Convenio Europeo de Derechos Humanos en un supuesto en el que el Tribunal Supremo admitió inicialmente un recurso de casación pero, cinco años después, lo inadmitió por sen-

${ }^{2}$ Disponibles en la página del Tribunal, en inglés y francés http://cmiskp.echr.coe.int 
tencia sin responder a las alegaciones relativas a los eventuales motivos de inadmisibilidad apreciados.

2) En la misma fecha, 22 de de julio, se dictó la sentencia del caso Gómez de Liaño c. España, en la que se apreció, por unanimidad, la violación del derecho a un tribunal imparcial al considerar que el Tribunal que debía juzgar al demandante por prevaricación ofrecía dudas de imparcialidad, pues todos sus miembros habían intervenido en numerosos actos de instrucción y, en particular, en la apelación contra el Auto de procesamiento dictado contra el demandante.

En cuanto a la composición del TEDH, Luis López Guerra asumió sus funciones el 1 de febrero, si bien Alejandro Saiz Arnaiz ejerció como Juez ad hoc en numerosos casos en los que no debía intervenir López Guerra.

\section{PARTIDOS POLÍTICOS Y PROCESOS ELECTORALES}

Respecto a las convocatorias electorales a lo largo del año 2008 han de citarse, en primer lugar, las elecciones generales de 9 de marzo. Antes de exponer los resultados debe recordarse que ya había entrado en vigor la reforma que realizó en la LOREG la Ley Orgánica 3/2007, de 22 de marzo, para la Igualdad efectiva de hombres y mujeres, que, en la materia que nos ocupa obliga a una composición equilibrada de hombres y mujeres en las listas electorales, de modo que las personas de cada sexo no superen el sesenta por ciento ni sean menos del cuarenta por ciento.

El Tribunal Constitucional se pronunció sobre la constitucionalidad de esta reforma en la STC 12/2008, de 29 de enero de 2008 que trae causa de la cuestión de inconstitucionalidad promovida por el Juzgado de lo Contencioso-Administrativo núm. 1 de Santa Cruz de Tenerife y el recurso de inconstitucionalidad interpuesto por más de cincuenta Diputados del Grupo Parlamentario Popular del Congreso de los Diputados.

En palabras del Tribunal:

«4. La primera y principal cuestión a resolver es la de la legitimidad constitucional de la imposición a los partidos políticos de la obligación de presentar candidaturas con «una composición equilibrada de mujeres y hombres» en porcentajes que siempre aseguren un mínimo del 40 por 100 para cada sexo. La respuesta hemos de buscarla tanto en el análisis del mandato de sustantivación de la igualdad formal, contenido en el artículo 9.2 CE, como en el de la configuración constitucional de los partidos políticos (artículo 6 CE). En cuanto al artículo 9.2 
CE .... expresa la voluntad del constituyente de alcanzar no sólo la igualdad formal sino también la igualdad sustantiva, al ser consciente de que únicamente desde esa igualdad sustantiva es posible la realización efectiva del libre desarrollo de la personalidad; por ello el constituyente completa la vertiente negativa de proscripción de acciones discriminatorias con la positiva de favorecimiento de esa igualdad material...

Este precepto constitucional encomienda al legislador la tarea de actualizar y materializar la efectividad de la igualdad que se proyecta, entre otras realidades, en el ámbito de la representación, correspondiendo a este Tribunal Constitucional la función de examinar si las decisiones adoptadas al respecto son acordes con el marco constitucional aquí definido. Pues bien, en particular del artículo 9.2 CE, y de la interpretación sistemática del conjunto de preceptos constitucionales que inciden en este ámbito, deriva la justificación constitucional de que los cauces e instrumentos establecidos por el Legislador faciliten la participación de todos los ciudadanos, removiendo, cuando sea preciso, los obstáculos de todo orden, tanto normativos como estrictamente fácticos, que la impidan o dificulten y promoviendo las condiciones garantizadoras de la igualdad de los ciudadanos. En este punto cabe añadir que la igualdad sustantiva no sólo facilita la participación efectiva de todos en los asuntos públicos, sino que es un elemento definidor de la noción de ciudadanía.

5. Dicho lo anterior, al preguntarnos sobre la legitimidad constitucional de la condición impuesta a los partidos por el artículo 44 bis LOREG, la respuesta, como razonaremos, ha de ser afirmativa, toda vez que los partidos políticos, como asociaciones cualificadas por sus funciones constitucionales (STC 48/2003, de 12 de marzo), son cauce válido para el logro de la sustantivación de la igualdad formal propugnada por el artículo 9.2 CE, precepto éste que dota de legitimidad a las configuraciones legislativas del estatuto jurídico de los partidos, o de sus actividades con relevancia pública, orientadas a la realización efectiva de un principio tan fundamental del orden constitucional como es el de la igualdad (arts. 1.1 y $14 \mathrm{CE})$.

Estas previsiones no suponen un tratamiento peyorativo de ninguno de los sexos, ya que, en puridad, ni siquiera plasman un tratamiento diferenciado en razón del sexo de los candidatos, habida cuenta de que las proporciones se establecen por igual para los candidatos de uno y otro sexo. No se trata, pues, de una medida basada en los criterios de mayoría/minoría (como sucedería si se tomase en cuenta como elementos de diferenciación, por ejemplo, la raza o la edad), sino atendiendo a un criterio (el sexo) que de manera universal divide a toda sociedad en dos grupos porcentualmente equilibrados.

Así pues el artículo 44 bis LOREG persigue la efectividad del artículo $14 \mathrm{CE}$ en el ámbito de la representación política, donde, si bien hombres y mujeres son formalmente iguales, es evidente que las segundas han estado siempre materialmente preteridas. Exigir de los partidos políticos que cumplan con su condición 
constitucional de instrumento para la participación política (artículo $6 \mathrm{CE}$ ), mediante una integración de sus candidaturas que permita la participación equilibrada de ambos sexos, supone servirse de los partidos para hacer realidad la efectividad en el disfrute de los derechos exigida por el artículo 9.2 CE. Y hacerlo, además, de una manera constitucionalmente lícita, pues con la composición de las Cámaras legislativas o de los Ayuntamientos se asegura la incorporación en los procedimientos normativos y de ejercicio del poder público de las mujeres (que suponen la mitad de la población) en un número significativo. Ello resulta coherente, en definitiva, con el principio democrático que reclama la mayor identidad posible entre gobernantes y gobernados...»

En cuanto a los resultados electorales, cabe mencionar los siguientes datos respecto al Congreso de los Diputados:

\begin{tabular}{|c|c|c|c|c|}
\hline \multicolumn{2}{|c|}{ Población de Derecho: 45.200 .737} & Votos Válidos: & 25.734 .866 & $99,36 \%$ \\
\hline Número de Mesas: & 59.346 & Votos Nulos: & 165.576 & $0,64 \%$ \\
\hline Censo Electoral: & 35.073 .179 & Votos Blancos: & 286.182 & $1,11 \%$ \\
\hline No Votantes: & $25.900 .44273,85 \%$ & Votos a Candidaturas: & 25.448 .684 & $98,89 \%$ \\
\hline Abstención: & $9.172 .73726,15 \%$ & & & \\
\hline Censo RAE: & 1.205 .329 & & & \\
\hline No Votantes RAE: & 382.568 & & & \\
\hline
\end{tabular}

En el Senado:

$\begin{array}{lrr}\text { No Votantes: } & 26.125 .239 & 74,49 \% \\ \text { Abstención: } & 8.947 .940 & 25,51 \% \\ \text { Censo RAE: } & 1.204 .700 & \\ \text { No Votantes RAE: } & 389.869 & \\ \text { Votos Válidos: } & 25.527 .940 & 97,71 \% \\ \text { Votos Nulos: } & 597.299 & 2,29 \% \\ \text { Votos Blancos: } & 524.750 & 2,06 \% \\ \text { Votos a Candidaturas: } & 25.003 .190 & 97,94 \%\end{array}$

Los resultados de las candidaturas que consiguieron escaños en el Congreso de los Diputados fueron los siguientes ${ }^{3}$ :

${ }^{3}$ Puede verse más información en http://www.elecciones.mir.es/MIR/jsp/resultados/index.htm 


\begin{tabular}{|c|c|c|c|c|}
\hline Candidatura & & Votos & \% Válidos & Diputados \\
\hline P.S.O.E. & Partido Socialista Obrero Español & 11.289 .335 & $43,87 \%$ & 169 \\
\hline P.P. & Partido Popular & 10.278 .010 & $39,94 \%$ & 154 \\
\hline CIU & Convergencia i Unio & 779.425 & $3,03 \%$ & 10 \\
\hline EAJ-PNV & $\begin{array}{l}\text { Euzko Alderdi Jeltzalea-Partido } \\
\text { Nacionalista Vasco }\end{array}$ & 306.128 & $1,19 \%$ & 6 \\
\hline ESQUERRA & Esquerra Republicana de Catalunya & 298.139 & $1,16 \%$ & 3 \\
\hline I.U. & Izquierda Unida & 969.946 & $3,77 \%$ & 2 \\
\hline B.N.G. & Bloque Nacionalista Galego & 212.543 & $0,83 \%$ & 2 \\
\hline CC-PNC & $\begin{array}{l}\text { Coalicion Canaria-Partido } \\
\text { Nacionalista Canario }\end{array}$ & 174.629 & $0,68 \% 2$ & \\
\hline UPYD & Union Progreso y Democracia & 306.079 & $1,19 \%$ & 1 \\
\hline NA-BAI & Nafarroa Bai & 62.398 & $0,24 \%$ & 1 \\
\hline
\end{tabular}

En el Senado

Candidatura

$\begin{array}{llr}\text { P.P. } & \text { Partido Popular } & 101 \\ \text { P.S.O.E. } & \text { Partido Socialista Obrero Español } & 89 \\ \text { PSC-ERC-ICV-EUIA } & & 12 \\ \text { CIU } & \text { Convergencia i Unio } & 4 \\ \text { EAJ-PNV } & \text { Euzko Alderdi Jeltzalea-Partido Nacionalista Vasco } & 2\end{array}$

El mismo día 8 de marzo también se celebraron elecciones al Parlamento de Andalucía, con los siguientes resultados para las candidaturas que obtuvieron escaños $^{4}$ :

Candidatura

Votos Diputados

P.S.O.E.

2.178 .296

56

P.P.

Partido Socialista Obrero Español

1.730 .154

47

IU

Izquierda Unida Los Verdes

317.56

26

En lo que respecta a la financiación de los partidos políticos, el Tribunal de Cuentas aprobó, en su sesión plenaria de 24 de abril de 2008, el «Informe de fiscalización de los estados contables del ejercicio 2005 de los Partidos Políticos con representación parlamentaria en las Cortes Generales o en las Asambleas legislativas de las Comunidades Autónomas»".

${ }^{4}$ Resultados completos en http://www.parlamentodeandalucia.es

5 Este Informe, como los anteriores, puede consultarse en la página del Tribunal de Cuentas http://www.tcu.es 
En su comparecencia, el 29 de abril de 2009, ante la Comisión Mixta para las Relaciones con el Tribunal de Cuentas, el Presidente de esta institución, D. Manuel Núñez Pérez, sintetizó las conclusiones y recomendaciones de la siguiente manera:

«En cuanto a la representatividad de las cuentas presentadas, en el informe se destaca, por un lado, la falta de fiscalización por no haberse remitido, de los estados financieros de una parte de las federaciones de Izquierda Unida, como se ha señalado, lo que supuso una importante limitación que impidió valorar adecuadamente los posibles efectos sobre las cuentas anuales; asimismo, se resalta que las deficiencias deducidas del examen de la documentación justificativa de los estados contables de la Chunta Aragonesista, Izquierda Unida y Partido Andalucista condicionaban la representatividad de las cuentas presentadas por dichas formaciones.

Se reitera en el informe, al igual que en ejercicios anteriores, que las cuentas anuales presentadas no recogen con carácter general la actividad económicofinanciera completa de la organización local ni la de los grupos de cargos electos en las corporaciones locales, especialmente por lo que se refiere a las cuotas de los afiliados recaudadas en dicho ámbito y a la actividad económica desarrollada en importantes municipios y, por otra parte, en la mayoría de las formaciones políticas con representación en el Parlamento Europeo no figura incluida la contabilidad de la representación parlamentaria.

Por lo que se refiere a las subvenciones otorgadas a los restantes grupos parlamentarios y su aplicación, en los apartados de cada formación política se expone el tratamiento contable seguido, observándose importantes diferencias entre ellos.

En cuanto a la financiación pública otorgada en el ejercicio 2005 a los partidos políticos para su funcionamiento ordinario, aquella alcanzó un total de 185 millones de euros, según información remitida al tribunal por las distintas instituciones. De este importe, 3 millones correspondían a la financiación estatal para gastos de seguridad otorgada a los partidos con representación en el Congreso de los Diputados. Además, las formaciones políticas percibieron subvenciones electorales por un total de 26 millones de euros, procedentes de los procesos electorales celebrados en el ejercicio fiscalizado y en anteriores. De las subvenciones para funcionamiento ordinario recibidas, 48 millones correspondían a subvenciones otorgadas por las corporaciones locales a los grupos políticos, y 5 millones de euros a las concedidas por el Gobierno del País Vasco para el funcionamiento ordinario de los partidos políticos con representación en el Parlamento vasco, recursos no incluidos entre las fuentes de financiación pública enumeradas en el artículo 2 de la Ley Orgánica de 1987. Asimismo, dentro de las subvenciones otorgadas a los grupos parlamentarios, ha de señalarse la subvención extraordinaria, por más de 7 millones, a la Generalidad de Cataluña, que se canalizó como 
subvención para funcionamiento ordinario de los partidos sin que se justificara su aplicación a esta finalidad.

En anexo al informe se relacionan las aportaciones entregadas por las entidades locales, en el que pueden comprobarse las significativas diferencias entre los importes otorgados por ayuntamientos de población similar como consecuencia de no disponer de unos límites y criterios comunes en esta materia. Se estima importante reseñar que en las sucesivas leyes de Presupuestos Generales del Estado no se estableció el límite de estas aportaciones previsto en la Ley de Bases del Régimen Local, concretamente en el artículo 63.

En cuanto a la financiación privada, con independencia de la financiación recibida a través de las cuotas de los militantes, las aportaciones no finalistas privadas sumaron 9 millones de euros, de los que 8 correspondían a aportaciones anónimas para las que, dada su naturaleza, no se pudo comprobar el cumplimiento del límite legal establecido en la normativa entonces aplicable para las aportaciones procedentes de una misma persona. No obstante, se ha comprobado que la cuantía total recibida por cada uno de los partidos no ha sobrepasado el límite fijado legalmente.

Respecto a las aportaciones nominativas, las procedentes de personas físicas, sumaron 0,7 millones de euros, y las de personas jurídicas sumaron 0,3 millones.

En cuanto al cumplimiento de los requisitos legales en las formaciones políticas Partido Andalucista, Partido Comunista de España y Partido Aragonés figuraban aportaciones no ingresadas en cuentas específicas.

Por lo que se refiere al endeudamiento, la deuda con entidades de crédito contabilizada, correspondiente a las formaciones políticas con representación en el Parlamento, en el Congreso de los Diputados y en el Senado, era de 145 millones de euros, de los que 6 millones correspondían a intereses. En cuanto a los partidos con representación en las asambleas legislativas de las comunidades autónomas, la deuda era de 11 millones de euros.

En las comprobaciones efectuadas sobre las operaciones de endeudamiento contabilizadas y la información ofrecida en las contestaciones recibidas como consecuencia de la circularización efectuada, se constató la existencia de diferencias debidas principalmente a los intereses devengados por operaciones vencidas y a las operaciones de la organización local no incluida en las cuentas presentadas. Por otra parte, existían operaciones que no habían sido objeto de amortización en los plazos vencidos. De acuerdo con los estados contables presentados, la deuda vencida total asciende al menos a 12 millones de euros de principal y a 8 millones de intereses, que se distribuye entre las formaciones políticas Eusko Alkartasuna, Izquierda Unida, Partido Andalucista, Partido Socialista Obrero Español y Unió Democràtica de Catalunya.

Se observó la existencia de regularizaciones de deuda con acreedores, con abono de resultados del ejercicio en la contabilidad de las formaciones políticas Partido Aragonés, Partido Nacionalista Vasco y PSM-Entesa Nacionalista de 
Mallorca por un total de 103.706 euros, 38.230 y 10.846, respectivamente, sin que los partidos hayan aportado documentación acreditativa de la cancelación de las deudas. Respecto a la regulación de obligaciones cuya extinción no está debidamente probada, el tribunal resalta que los partidos deberían emplear todos los procedimientos a su alcance a fin de cumplir con las obligaciones contraídas.

Otros resultados que podríamos destacar del informe son que en el año 2005 continuaron las devoluciones realizadas por el Estado al amparo de la Ley 43/1998, de 15 de diciembre, de Restitución o Compensación a los Partidos Políticos de Bienes y Derechos Incautados en aplicación de la normativa sobre responsabilidades políticas del período 1936/1939, habiéndose producido una compensación pecuniaria a la formación política Partido Socialista Obrero Español por 2,8 millones de euros. Se constató, asimismo, que diversas formaciones políticas como Convergència Democràtica de Catalunya, Eusko Alkartasuna y Partido Nacionalista Vasco mantenían participaciones, generalmente por el total del capital social, en sociedades mercantiles cuya actividad principal era la tenencia y administración de bienes inmuebles vinculados al desarrollo de actividades propias del partido, así como, en el caso del Partido Nacionalista Vasco, también en la gestión inmobiliaria de sedes del partido y otros servicios. En esta área se constató también que el Partido Socialista de Cataluña tenía registrada una participación en una sociedad editora procedente de una donación.

Como en anteriores informes, se señalan las relaciones que la mayoría de los partidos políticos mantenían con diversas fundaciones, como las relativas a su constitución, a la concesión de préstamos de subvenciones de funcionamiento, a la adquisición de inmuebles por parte de la fundación y la posterior cesión a uso del partido, al ingreso de la fundación de las aportaciones realizadas por los cargos públicos y, por último, a la prestación de aval por parte del partido en operaciones de deuda suscritas por la fundación. En este ejercicio se entregaron fondos a fundaciones por un total de 2 millones, y se mantenían saldos acreedores relacionados con ellas por 4 millones de euros. Cabe recordar que la nueva Ley sobre financiación de los partidos políticos avanza considerablemente en el control de las fundaciones.

¿Qué recomendaciones hace este informe...? En relación con la subvención para gastos de seguridad, se reitera la propuesta formulada en informes anteriores de que, a efectos de garantizar una mayor seguridad jurídica y facilitar su fiscalización, se acometa el desarrollo normativo. Asimismo, y a fin de garantizar un procedimiento de justificación homogéneo y un adecuado control de la dotación económica asignada a los grupos políticos, se formula la recomendación de que dichas asignaciones sean también objeto de una regulación específica.

Por último, al haberse derogado la ley orgánica vigente durante el fiscalizado ejercicio 2005, en la nueva Ley Orgánica de 2007 sobre financiación de los partidos políticos se anuncia que, al efectuarse la fiscalización del ejercicio en el que esta nueva ley sea de aplicación, se evaluará si han atendido las recomendaciones y 
si han quedado subsanadas o no las insuficiencias normativas puestas de manifiesto por el tribunal en la moción que fue elevada en su momento a las Cortes Generales y de la que parte fundamentalmente la modificación de la ley vigente.

Como posibles responsabilidades, tengo que decir que, remitido el proyecto de informe al Servicio Jurídico del Estado y al ministerio fiscal del tribunal, ambos manifestaron su conformidad con su contenido y no apreciaron ningún signo, ningún supuesto de responsabilidad».

\section{ÓRGANOS CONSTITUCIONALES Y AUTONÓMICOS}

Por lo que respecta a la actividad legislativa de las Cortes Generales, se aprobaron a lo largo del año 20082 Leyes Orgánicas ${ }^{6}$ y 4 Leyes Ordinarias . Como ocurre el primer año de cada Legislatura, el número de leyes aprobadas (6) es notablemente inferior que en los años precedentes: 36 en 2005, 52 en 2006 y 68 en 2007.

A propósito de los Órganos Auxilares de las Cortes Generales, el Defensor del Pueblo presentó, el 16 de septiembre, ante la Comisión Mixta para las Relaciones con el Defensor del Pueblo, el Informe correspondiente al año $2007^{8}$ en el que se concluye, entre otras cosas, lo siguiente:

${ }^{6}$ Ley Orgánica 1/2008, de 30 de julio, por la que se autoriza la ratificación por España del Tratado de Lisboa, por el que se modifican el Tratado de la Unión Europea y el Tratado Constitutivo de la Comunidad Europea, firmado en la capital portuguesa el 13 de diciembre de 2007 (BOE núm. 184, de 31 de julio de 2008) y la Ley Orgánica 2/2008, de 4 de diciembre, de modificación de la Ley Orgánica 6/1985, de 1 de julio, del Poder Judicial, complementaria de la Ley para la ejecución en la Unión Europea de Resoluciones que impongan sanciones pecuniarias (BOE núm. 293, de 5 de diciembre de 2008). Pueden consultarse su tramitación parlamentaria y el texto oficial en la página del Congreso de los Diputados: http://www.congreso.es/portal/page/portal/Congreso/Congreso/Iniciativas

${ }^{7}$ Ley 1/2008, de 4 de diciembre, para la ejecución en la Unión Europea de resoluciones que impongan sanciones pecuniarias (BOE núm. 293, de 5 de diciembre de 2008); Ley 2/2008, de 23 de diciembre, de Presupuestos Generales del Estado para el año 2009 (BOE núm. 309, de 24 de diciembre de 2008); Ley 3/2008, de 23 de diciembre, relativa al derecho de participación en beneficio del autor de una obra de arte original (BOE núm. 310, de 25 de diciembre de 2008) y Ley 4/2008, de 23 de diciembre, por la que se suprime el gravamen del Impuesto sobre el Patrimonio, se generaliza el sistema de devolución mensual en el Impuesto sobre el Valor Añadido, y se introducen otras modificaciones en la normativa tributaria (BOE núm. 310, de 25 de diciembre de 2008).

Pueden consultarse su tramitación parlamentaria y el texto oficial en la página del Congreso de los Diputados: http:/www.congreso.es/portal/page/portal/Congreso/Congreso/Iniciativas

8 Disponible en http://www.defensordelpueblo.es/index.asp?destino=informes1.asp

(C) UNED. Revista de Derecho Político 
El total de expedientes de queja abiertos por la institución el pasado año alcanzó la cifra de 17.373, y en ellos se incluyen las quejas individuales, las colectivas y las investigaciones de oficio. Tras esos expedientes se encontraban las peticiones de 38.738 ciudadanos, que formularon su personal reclamación y fueron oportunamente atendidos. Los servicios de la institución gestionaron 262 quejas de oficio, cuando el año precedente habían gestionado solo 142; o sea, un total de 120 más, lo que representa un incremento de casi un 85 por ciento.

Otros aspectos destacables en cuanto a la estadística de las quejas tienen que ver con su procedencia geográfica, con su clasificación según las materias de que tratan y con su estado de tramitación. La inmensa mayoría de las reclamaciones, en concreto 16.726 , procede, como es natural, de territorio español y tan solo 385 llegaron desde el extranjero. Por comunidades autónomas sigue apareciendo la comunidad madrileña en primer lugar, con más de 4.800 quejas, seguida en esta ocasión por la comunidad catalana, con casi 2.200, y la andaluza, con algo más de $1.750 .$.

Más importante y orientadora es, a todas luces, la clasificación de las quejas por su propio contenido...Así, resulta evidente la estabilización de las reclamaciones ciudadanas sobre sanidad y política social, que incluyen las quejas relacionadas con la salud, las prestaciones sociales y los colectivos dependientes, como los ancianos y las personas con discapacidad. También se mantienen las cifras en el sector del empleo público, en las que aparecen las de quienes prestan servicios en todas las administraciones y el personal perteneciente a las Fuerzas Armadas y de las Fuerzas y Cuerpos de Seguridad del Estado. Parecido nivel alcanzan las quejas que afectan a las funciones de Interior, sobre todo seguridad ciudadana y seguridad vial, y las que se engloban en el capítulo de Justicia, incluidos los casos de violencia doméstica. Asimismo confirman su apuntado crecimiento las quejas sobre inmigración y las que plantean asuntos dependientes de las administraciones económicas, en las que se agrupan, entre otras, las cuestiones tributarias y las que tienen que ver con las telecomunicaciones. Finalmente, a pesar de su trascendencia, hay que mencionar el crecimiento y la importancia de las quejas sobre ordenación del territorio y medio ambiente, entre las que se encuentran las concernientes a urbanismo y vivienda.

En lo relativo al proceso investigador de los expedientes, se admitió a trámite más del 41 por ciento de las quejas presentadas...

Las resoluciones dirigidas a las administraciones como consecuencia de los expedientes gestionados alcanzaron a 31 de diciembre de 2007 unos totales de 156 recomendaciones, 204 sugerencias, 108 recordatorios de deberes legales y una advertencia... A mediados del mes de julio de 2007 se habían recibido respuestas de las distintas administraciones para 140 de las recomendaciones, de las que 107 se declaraban admitidas y 33 rechazadas. De las sugerencias, a la misma fecha, se habían admitido 110 y rechazado 67 por distintos motivos. Estas cifras reflejan, señorías, una de las tasas más altas de aceptación de nuestras resolucio- 
nes. En conjunto se superó el umbral del 60 por ciento de propuestas aceptadas por las administraciones, llegando casi al 70 por ciento en lo que se refiere a la aceptación de recomendaciones.

En el marco de las resoluciones del Defensor del Pueblo merecen párrafo aparte, por su especial complejidad y trascendencia jurídica, las producidas como consecuencia de las peticiones formuladas para el ejercicio de la legitimación constitucional activa dirigida a la interposición de recursos de inconstitucionalidad y amparo. Durante el ejercicio 2007 se recibieron más de 700 peticiones de particulares y entidades para ejercer esa legitimación sobre un total de 16 normas, entre las que destacan las leyes orgánicas de reforma de los estatutos de autonomía de las Illes Balears, Andalucía y Aragón y la Ley orgánica para la igualdad efectiva de hombres y mujeres.

... mencionaré tan solo las administraciones más pertinaces en el incumplimiento. La Administración General del Estado tiene tres dependencias afectadas: la Dirección General de Aviación Civil y la Demarcación de Carreteras del Estado en Málaga, ambas en la órbita del Ministerio de Fomento, y la Dirección General de Tráfico, del Ministerio del Interior. En la Administración autonómica se encuentran también en esa situación la Agencia Andaluza del Agua, la sociedad anónima Viviendas del Principado de Asturias, la Consejería de Medio Ambiente y Ordenación del Territorio y la Consejería de Vivienda, ambas de la Comunidad de Madrid, y la Consejería valenciana de Medio Ambiente, Agua, Urbanismo y Vivienda. En cuanto a la Administración local, se hallan incursos en incumplimiento crónico hasta 34 ayuntamientos, entre ellos los de las capitales provinciales de Burgos, Cáceres, Castellón de la Plana, Ciudad Real y Oviedo...

En cuanto a la composición del Gobierno, José Luis Rodríguez Zapatero fue investido como Presidente el 11 de abril al obtener, con 169 votos, la confianza por mayoría simple del Congreso de los Diputados. En una primera votación, el 9 de abril, no consiguió la mayoría absoluta exigida por la Constitución.

A continuación formó el primer Gobierno de la IX Legislatura con la siguiente composición: María Teresa Fernández de la Vega, Vicepresidenta Primera, Ministra de la Presidencia y Portavoz del Gobierno; Pedro Solbes, Vicepresidente Segundo y Ministro de Economía y Hacienda; Alfredo Pérez Rubalcaba, Ministro del Interior; Elena Salgado, Ministra de Administraciones Públicas; Carme Chacón, Ministra de Defensa; Celestino Corbacho, Ministro de Trabajo e Inmigración; Mariano Fernández Bermejo, Ministro de Justicia; Bernat Soria, Ministro de Sanidad; Miguel Ángel Moratinos, Ministro de Asuntos Exteriores; Miguel Sebastián, Ministro de Industria, Turismo y Comercio; Mercedes Cabrera, Ministra de Educación, Asuntos sociales y Familia; César Antonio Molina, Ministro de Cultura; Elena Espinosa; Ministra de Agricultura y 
Medio ambiente; Cristina Garmendia, Ministra de Investigación y Desarrollo; Magdalena Álvarez, Ministra de Fomento; Bibiana Aido, Ministra de Igualdad; Beatriz Corredor, Ministra de Vivienda.

Debe recordarse que el gabinete se organizó a través del Real Decreto $525 / 2008$, de 25 de abril, y la estructura orgánica de los Ministerios por medio del Real Decreto 438/2008, de 14 de abril.

En febrero de 2009 Francisco Caamaño fue nombrado Ministro de Justicia tras la dimisión de Mariano Fernández; en abril de 2009, el Presidente sustituyó a varios de los miembros del Consejo de Ministros: Elena Salgado pasó a ser Vicepresidenta Segunda y Ministra de Economía y Hacienda; Manuel Chaves Vicepresidente Tercero y Ministro de Política Territorial; José Blanco fue nombrado Ministro de Fomento, Ángel Gabilondo de Educación, Trinidad Jiménez de Sanidad y Políticas Sociales y Ángeles González Sinde de Cultura.

Por lo que se refiere a la actividad legislativa del Gobierno, se aprobaron 10 Decretos-Ley y 2 Decretos Legislativos?

9 Real Decreto-Ley 1/2008, de 18 de enero, por el que se determina el Indicador Público de Renta de Efectos Múltiples (IPREM) para 2008 y se concede un crédito extraordinario en el Presupuesto del Ministerio de Trabajo y Asuntos Sociales, por importe de 200.000.000 euros con destino a la acogida e integración de inmigrantes, así como al refuerzo educativo de los mismos (BOE núm. 17, de 19 de enero); Real Decreto-Ley 2/2008, de 21 de abril, de medidas de impulso a la actividad económica (BOE núm. 97, de 22 de abril); Real Decreto-Ley 3/2008, de 21 de abril, de medidas excepcionales y urgentes para garantizar el abastecimiento de poblaciones afectadas por la sequía en la provincia de Barcelona (BOE núm. 97, de 22 de abril); Real Decreto-Ley 4/2008, de 19 de septiembre, sobre abono acumulado y de forma anticipada de la prestación contributiva por desempleo a trabajadores extranjeros no comunitarios que retornen voluntariamente a sus países de origen (BOE núm. 228, de 20 de septiembre); Real Decreto-Ley 5/2008, de 3 de octubre, por el que se autoriza a la Administración General del Estado a formalizar un contrato de garantía con el Banco Europeo de Inversiones y se amplía el límite para el otorgamiento de avales fijado en el artículo 54 de la Ley 51/2007, de 26 de diciembre, de Presupuestos Generales del Estado para 2008 (BOE núm. 240, de 4 de octubre); Real Decreto-Ley 6/2008, de 10 de octubre, por el que se crea el Fondo para la Adquisición de Activos Financieros (BOE núm. 248, de 14 de octubre); Real Decreto-Ley 7/2008, de 13 de octubre, de Medidas Urgentes en Materia Económico-Financiera en relación con el Plan de Acción Concertada de los Países de la Zona Euro (BOE núm. 248, de 14 de octubre); Real Decreto-Ley 8/2008, de 24 de octubre, por el que se adoptan medidas urgentes para paliar los efectos producidos por la sequía en determinados ámbitos de las cuencas hidrográficas (BOE núm. 258, de 25 de octubre); Real Decreto-Ley 9/2008, de 28 de noviembre, por el que se crean un Fondo Estatal de Inversión Local y un Fondo Especial del Estado para la Dinamizacion de la Economía y el Empleo y se aprueban créditos extraordinarios para atender a su financiación (BOE núm. 290, de 2 de diciembre); Real Decreto-Ley 10/2008, de 12 de diciembre, por el que se adoptan medidas financieras para la mejora de la liquidez de las pequeñas y medianas empresas, y otras medidas económicas complementarias (BOE núm. 300, de 13 de diciembre). 
A propósito de las Asambleas Legislativas de las Comunidades Autónomas procede recordar que se aprobaron dos nuevos reglamentos parlamentarios: el de la Asamblea de Extremadura (de 19 de junio de 2008) ${ }^{10}$ y el del Parlamento Vasco (publicado en el Boletín Oficial de la Cámara el 29 de diciembre de 2008) $)^{11}$.

Llama la atención que ambas normas introducen novedades importantes en materia de ejercicio del voto en la actividad parlamentaria:

El primero dispone en su artículo 144 que «en los supuestos de investidura del Presidente de la Junta de Extremadura, moción de censura y cuestión de confianza, las votaciones serán siempre públicas por llamamiento. En dichos supuestos, los diputados que por hospitalización o convalecencia se vean imposibilitados para asistir al Pleno podrán, previa acreditación de su situación, emitir su voto en la forma y con las garantías que se dispongan por acuerdo de la Mesa de la Cámara. En el mismo supuesto se encontrarán las Diputadas que no puedan asistir a las sesiones plenarias por causas de embarazo o parto".

El segundo establece en su artículo 88 que «1. El voto de las parlamentarias y parlamentarios es personal e indelegable, salvo en los siguientes supuestos: a) Las parlamentarias dispondrán de un periodo de descanso por maternidad de seis semanas posteriores al parto. Durante este periodo podrán delegar su voto en la portavoz o el portavoz o en otra parlamentaria o parlamentario. b) Las parlamentarias y parlamentarios que con motivo de la maternidad o paternidad no puedan cumplir su deber de asistir a los debates y votaciones del pleno podrán delegar su voto en la portavoz o el portavoz o en otra parlamentaria o parlamentario. La delegación de voto debe realizarse mediante escrito dirigido a la Mesa del Parlamento, en el cual deben constar los nombres de la persona que delega el voto y de la que recibe la delegación, así como los debates y las votaciones donde debe ejercerse o, en su caso, el periodo de duración de la delegación. La Mesa, al admitir a trámite la solicitud, establecerá el procedimiento para ejercer el voto delegado y el tiempo máximo».

En el ámbito de los Gobiernos de las Comunidades Autónomas, tras las elecciones parlamentarias de Andalucía, Manuel Chaves fue elegido Presidente con los votos favorables de los 56 Diputados del Partido Socialista Obrero Español. En abril de 2009 fue investido nuevo Presidente José Antonio Griñán.

Real Decreto Legislativo $1 / 2008$, de 11 de enero, por el que se aprueba el texto refundido de la Ley de Evaluación de Impacto Ambiental de proyectos (BOE núm. 23, de 26 de enero) y Real Decreto Legislativo 2/2008, de 20 de junio, por el que se aprueba el texto refundido de la ley de suelo (BOE núm. 154, de 26 de junio).

${ }_{10}$ Consultado en http://www.asambleaex.es/descargas/pdfs/reglamento/reglamento2008.pdf

11 En http://parlamento.euskadi.net 
Respecto de los órganos de las Comunidades Autónomas y sus instituciones auxiliares y consultivos, se aprobaron la Ley Foral 3/2008, de 21 de febrero de 2008 de la Comunidad Foral de Navarra por la que se modifica el artículo 2 de la Ley Foral 4/2000, de 3 de julio, del Defensor del Pueblo de la Comunidad Foral de Navarra (BOE ${ }^{\circ} 65$, de 15 de marzo; $B O N n^{\circ} 29$, de 3 de marzo); la Ley $1 / 2008$, de 19 de mayo de 2008, de Reforma de la Ley 6/2006, de 2 de mayo, del Defensor del Pueblo Riojano (BOR n ${ }^{\circ}$ 67, de 20 de mayo, BOE n ${ }^{\circ}$ 135, de 4 de junio); la Ley 6/2008, de 15 de octubre de 2008, de modificación de la Ley 2/2002, de 9 de abril, reguladora del Consejo de Cuentas de Castilla y León (BOCL ${ }^{\circ} 203$, de 21 de octubre, BOE $n^{\circ} 261$, de 26 de octubre) y la Ley 4/2008, de 24 de noviembre de 2008, de segunda modificación de la Ley del Principado de Asturias 8/1991, de 30 de julio, de Organización de la Administración (BOPA n ${ }^{\circ} 274$, de 25 de noviembre, $\mathrm{BOE} \mathrm{n}^{\circ} 22$, de 26 de enero de 2009).

Por lo que al Tribunal Constitucional se refiere, ha de mencionarse, como se recuerda en su Memoria del año $2008^{12}$, que el año ha traído dos importantes novedades. En primer lugar, las Salas han dictado varias resoluciones en procedimientos de inconstitucionalidad, deferidos a su conocimiento por el Pleno en virtud del nuevo artículo 10 LOTC, reformado por la Ley Orgánica 6/2007, de 24 de mayo: dos Sentencias (SSTC 126/2008, de 27 de octubre, y 162/2008, de 15 de diciembre); un Auto de extinción (ATC 381/2008, de 15 de diciembre) y dos Autos interlocutorios, sobre personación en un recurso de inconstitucionalidad y sobre suspensión de la vigencia de leyes impugnadas (AATC 247/2008 y 248/2008, ambos de 24 de julio). Asimismo, las Secciones han empezado a resolver los recursos de amparo que les defieren la Salas, en virtud de la nueva redacción del artículo 52 de la Ley Orgánica del Tribunal.

En relación con el control de constitucionalidad de disposiciones legales, deben citarse las siguientes sentencias ${ }^{13}$ :

1) La STC 49/2008, de 9 de abril, declaró la constitucionalidad de dos de las reformas introducidas por la Ley Orgánica 6/2007, de 24 de mayo, en la Ley Orgánica 2/1979, de 3 de octubre, del Tribunal Constitucional: la participación de las Comunidades Autónomas en la elección de Magistrados del Tribunal Constitucional por parte del Senado; y la prórroga de la duración de la Presidencia en los supuestos en que su mandato no coincida con la renovación parcial del Tribunal.

\footnotetext{
12 Disponible en http://www.tribunalconstitucional.es

13 Pueden verse en http://www.tribunalconstitucional.es/JC.htm
} 
En palabras del Tribunal, «ningún precepto constitucional impide expresamente que las Asambleas de las Comunidades Autónomas puedan intervenir en la elección presentando candidatos al Senado; aunque esa intervención no está prevista, no puede interpretarse como una prohibición constitucional implícita. De la interpretación de los artículos 69 y 159.1 CE puede derivarse un principio de participación autonómica en la composición del Tribunal, que es susceptible de ser desarrollado de diversos modos. Y la intensidad de esa participación, que se limita a la fase de presentación de candidatos, no implica que el Senado deje de ser titular de la facultad de elegir a los miembros del Tribunal.

Respecto a la prórroga de la Presidencia, señala el Tribunal que «es que la pretensión de hacer coincidir la renovación parcial del Tribunal con la elección interna de su Presidencia no puede considerarse arbitraria. Por otro lado, dicha finalidad tampoco puede considerarse en sí misma vulneradora de ningún otro precepto constitucional, puesto que lo que se pretende es armonizar diversos aspectos del modelo organizativo del Tribunal Constitucional que se derivan de los artículos 159.3 y $160 \mathrm{CE}$ a los que ya hemos hecho referencia. Concretamente, que su renovación parcial se produzca cada tres años, que en la elección de la Presidencia participen los miembros del Tribunal, y que el mandato de la Presidencia sea también de tres años. Aunque dicha armonización no siempre puede ser absoluta ni existe un único medio para alcanzarla, interesa destacar que durante todo el proceso constituyente se mantuvo la coincidencia temporal entre la renovación parcial del Tribunal y la duración del mandato presidencial, hasta el punto que incluso alguna de las enmiendas que pretendieron reducir el lapso de tiempo entre las diversas renovaciones también redujo el mandato presidencial por el mismo período (este fue el caso, concretamente, de la enmienda núm. 697). Desde esta perspectiva, pues, la finalidad perseguida por la norma impugnada no sólo no es en sí misma inconstitucional, sino que también puede considerarse constitucionalmente legítima. La legitimidad constitucional de la medida impugnada también se deduce, por otro lado, de su repercusión en el funcionamiento y en el modelo organizativo del Tribunal Constitucional. Pretender, en efecto, que sea el Pleno renovado el que elija la Presidencia permite que este órgano continúe ejerciendo sus competencias con normalidad hasta que la renovación del Tribunal se produzca. Al mismo tiempo, refuerza la figura de la Presidencia tanto antes como después de la renovación, puesto que garantiza que el colegio de Magistrados sea presidido en todo momento por un miembro del Tribunal elegido con el concurso de todos sus integrantes.

La prórroga del mandato presidencial no es asimilable, en efecto, a un fraccionamiento de dicho mandato ni a una restricción del número o del nombre de los candidatos a ocupar la Presidencia,... En segundo lugar, también debemos rechazar que la norma impugnada vulnere el artículo $160 \mathrm{CE}$, puesto que lo que se prevé en la misma es una prórroga del mandato presidencial vigente y no un nuevo nombramiento. Como consecuencia de tal prórroga es evidente que el man- 
dato presidencial se prolonga más allá de los tres años previstos por dicho precepto, pero sólo desde una interpretación inadecuada del mismo que confunda la temporalidad del mandato con la posibilidad de su prórroga y que no tenga en cuenta la necesidad de armonizar otros bienes jurídicos constitucionales es posible derivar de esta circunstancia la inconstitucionalidad del precepto impugnado».

2) La Sentencia 101/2008, de 24 de julio, en coherencia con la anterior, desestima el recurso de inconstitucionalidad contra el artículo 184.7 del Reglamento del Senado, introducido por el artículo único de la Reforma de dicho Reglamento de 21 de noviembre de 2007, donde se aprobó el procedimiento para elegir los Magistrados constitucionales con participación de las Comunidades Autónomas. Según esta sentencia,

«ninguna objeción cabe formular a que la Cámara Alta haya de limitarse, en principio, a elegir, como indica el artículo 16.1 LOTC, entre los candidatos previamente presentados por las Asambleas Legislativas autonómicas y en esa forma lo establezca en su Reglamento, pues, en todo caso, interpretado el precepto reglamentario en los términos expresados en la presente Sentencia, se garantiza que la misma pueda cumplir con la dicha función constitucional, eligiendo a otros candidatos posibles surgidos de su propio seno, en el caso de que no resulte posible cubrir todos o alguno de los puestos de Magistrados del Tribunal Constitucional por no obtener la mayoría de tres quintos los presentados por las Asambleas Legislativas de las Comunidades Autónomas.... En mérito de lo expuesto, y así interpretado el precepto impugnado podemos apreciar que el Reglamento del Senado, cuyo contenido propio es el de regular, con sujeción a la Constitución, su propia organización y funcionamiento rigiendo el ejercicio de las competencias que corresponden a la Cámara, ha velado adecuadamente por el ejercicio constitucionalmente correcto de esta concreta función de designación atribuida a la Cámara, evitando tanto el riesgo de bloqueo en su ejercicio como que la misma pueda quedar vacía materialmente de contenido»

3) La STC 59/2008, de 14 de mayo, es la primera de las 12 que rechazaron la inconstitucionalidad del artículo 153.1 del Código penal, redactado por la Ley Orgánica 1/2004, de 28 de diciembre, de medidas de protección integral contra la violencia de género ${ }^{14}$ :

Entre otras cosas, sostiene el Tribunal que

14 «El que por cualquier medio o procedimiento causare a otro menoscabo psíquico o una lesión no definidos como delito en este Código, o golpeare o maltratare de obra a otro sin causarle lesión, cuando la ofendida sea o haya sido esposa, o mujer que esté o haya estado ligada a él por una análoga relación de afectividad aun sin convivencia ... será castigado con la pena de prisión de seis meses a un año". 
«No resulta reprochable el entendimiento legislativo referente a que una agresión supone un daño mayor en la víctima cuando el agresor actúa conforme a una pauta cultural — la desigualdad en el ámbito de la pareja — generadora de gravísimos daños a sus víctimas y dota así consciente y objetivamente a su comportamiento de un efecto añadido a los propios del uso de la violencia en otro contexto. Por ello, cabe considerar que esta inserción supone una mayor lesividad para la víctima: de un lado, para su seguridad, con la disminución de las expectativas futuras de indemnidad, con el temor a ser de nuevo agredida; de otro, para su libertad, para la libre conformación de su voluntad, porque la consolidación de la discriminación agresiva del varón hacia la mujer en el ámbito de la pareja añade un efecto intimidatorio a la conducta, que restringe las posibilidades de actuación libre de la víctima; y además para su dignidad, en cuanto negadora de su igual condición de persona y en tanto que hace más perceptible ante la sociedad un menosprecio que la identifica con un grupo menospreciado. No resulta irrazonable entender, en suma, que en la agresión del varón hacia la mujer que es o fue su pareja se ve peculiarmente dañada la libertad de ésta; se ve intensificado su sometimiento a la voluntad del agresor y se ve peculiarmente dañada su dignidad, en cuanto persona agredida al amparo de una arraigada estructura desigualitaria que la considera como inferior, como ser con menores competencias, capacidades $\mathrm{y}$ derechos a los que cualquier persona merece.

No es el sexo en sí de los sujetos activo y pasivo lo que el legislador toma en consideración con efectos agravatorios, sino — una vez más importa resaltarlo- el carácter especialmente lesivo de ciertos hechos a partir del ámbito relacional en el que se producen y del significado objetivo que adquieren como manifestación de una grave y arraigada desigualdad. La sanción no se impone por razón del sexo del sujeto activo ni de la víctima ni por razones vinculadas a su propia biología. Se trata de la sanción mayor de hechos más graves, que el legislador considera razonablemente que lo son por constituir una manifestación específicamente lesiva de violencia y de desigualdad..."

4) La Sentencia 103/2008, de 11 de septiembre, declaró la nulidad de la Ley del Parlamento Vasco 9/2008, de 27 de junio, de convocatoria y regulación de una consulta popular al objeto de recabar la opinión ciudadana en la Comunidad Autónoma del País Vasco sobre la apertura de un proceso de negociación para alcanzar la paz y la normalización política. En palabras del Tribunal:

«La cuestión que ha querido someterse a consulta de los ciudadanos de la Comunidad Autónoma del País Vasco afecta (artículo 2 CE) al fundamento del orden constitucional vigente (en la medida en que supone la reconsideración de la identidad y unidad del sujeto soberano o, cuando menos, de la relación que únicamente la voluntad de éste puede establecer entre el Estado y las Comuni- 
dades Autónomas) y por ello sólo puede ser objeto de consulta popular por vía del referéndum de revisión constitucional. Es un asunto reservado en su tratamiento institucional al procedimiento del artículo $168 \mathrm{CE}$. La que aquí nos ocupa no puede ser planteada como cuestión sobre la que simplemente se interesa el parecer no vinculante del cuerpo electoral del País Vasco, puesto que con ella se incide sobre cuestiones fundamentales resueltas con el proceso constituyente y que resultan sustraídas a la decisión de los poderes constituidos. El respeto a la Constitución impone que los proyectos de revisión del orden constituido, y especialmente de aquéllos que afectan al fundamento de la identidad del titular único de la soberanía, se sustancien abierta y directamente por la vía que la Constitución ha previsto para esos fines. No caben actuaciones por otros cauces ni de las Comunidades Autónomas ni de cualquier órgano del Estado, porque sobre todos está siempre, expresada en la decisión constituyente, la voluntad del pueblo español, titular exclusivo de la soberanía nacional, fundamento de la Constitución y origen de cualquier poder político...»

5) La STC 162/2008, de 15 de diciembre, es la primera en la que una Sala declara nula una disposición con rango de ley: el precepto de la Ley 21/1992, de 16 de julio, de industria, que tipificaba como infracción administrativa leve el incumplimiento de «cualquier otra prescripción reglamentaria no incluida en los apartados anteriores», que enumeran las infracciones muy graves y graves. $\mathrm{Y}$ es que si bien el precepto ostenta rango de ley, no contiene los elementos esenciales de la conducta antijurídica, con lo que permite una regulación reglamentaria independiente, lo que no cumple con las exigencias del principio de legalidad en materia sancionadora.

\section{ORGANIZACIÓN TERRITORIAL DEL ESTADO}

Ya se han mencionado las elecciones al Parlamento de Andalucía y la elección del Presidente de esa Comunidad Autónona. También la STC 103/2008, de 11 de septiembre, que declaró la nulidad de la Ley del Parlamento Vasco 9/2008, de 27 de junio, de convocatoria y regulación de una consulta popular.

El Tribunal, además, inadmitió a trámite, por notoriamente infundadas, varias cuestiones de inconstitucionalidad que se referían a leyes autonómicas: la Ley del Parlamento de Andalucía 18/2003, de 29 de diciembre, de medidas fiscales y administrativas, cuyos artículos 56 a 64 establecían y regulaban un impuesto sobre el depósito de residuos radioactivos; la Ley de las Cortes de Aragón 18/2006, de 29 de diciembre, de presupuestos, sobre retribuciones del personal 
interino, que no altera el estatuto marco del personal estatutario de los servicios de salud, aprobado por Ley de Cortes Generales 55/2003, de 16 de diciembre; la Ley de las Cortes de Castilla-La Mancha 5/1986, de 23 de diciembre, electoral de la Comunidad Autónoma, que si bien al distribuir los escaños del Parlamento entre las provincias no se ajusta al número real de habitantes que existía en cada una de ellas en el momento de convocar las elecciones de 2007, no vulnera el principio de representación proporcional establecido por la Constitución porque, por razones vinculadas con la efectividad en la actuación y organización del poder público autonómico, las distorsiones de la proporcionalidad originadas por el mero paso del tiempo y la evolución de los flujos poblacionales no siempre podrán ser corregidas de manera inmediata por el legislador; la Ley del Parlamento de Galicia 5/1999, de 21 de mayo, de ordenación farmacéutica, que no vulnera la legislación básica sobre sanidad aunque permita que, en determinadas circunstancias excepcionales, la dispensación de medicamentos pueda realizarse por persona distinta del farmacéutico.

En el ámbito de la Administración Local, la Sentencia 47/2008, de 11 de marzo, declaró extinguido el conflicto en defensa de la autonomía local promovido por varios Ayuntamientos respecto a la Ley de la Generalitat Valenciana 8/1999, de 3 de diciembre, que suprimió el Área Metropolitana de l'Horta.

En el derecho autonómico se aprobaron la Ley 8/2008 de 5 de junio de 2008 de modificación de la Ley 23/2006, de 20 de diciembre, de capitalidad de Palma de Mallorca (BOB no 87, Fascículo 1, de 21 de junio; BOE no ${ }^{\circ} 170$, de 15 de julio) y, en Galicia, la Ley 12/2008 de 3 de diciembre de 2008 por la que se modifican la Ley 7/1996, de 10 de julio, de desarrollo comarcal, y la Ley $5 / 2000$, de 28 de diciembre, de medidas fiscales y de régimen presupuestario y administrativo, y se racionalizan los instrumentos de gestión comarcal y de desarrollo rural (DOG $\mathrm{n}^{\circ} 244$, de17 de diciembre; BOE $\mathrm{n}^{\circ}$ 15, de 17 de enero de 2009).

\section{DERECHOS, DEBERES Y LIBERTADES}

En primer lugar, y por seguir la ubicación de las materias en el articulado de la Constitución, ha de mencionarse, en materia de igualdad, que el Tribunal rechazó, como ha hemos visto, la inconstitucionalidad tanto del nuevo artículo 44 bis de la LOREG (STC 12/2008) como del artículo 153.1 del Código penal, redactado por la Ley Orgánica 1/2004, de 28 de diciembre, de medidas de protección integral contra la violencia de género (STC 59/2008). Como ya se ha apuntado más arriba 
«No resulta reprochable el entendimiento legislativo referente a que una agresión supone un daño mayor en la víctima cuando el agresor actúa conforme a una pauta cultural — la desigualdad en el ámbito de la pareja — generadora de gravísimos daños a sus víctimas y dota así consciente y objetivamente a su comportamiento de un efecto añadido a los propios del uso de la violencia en otro contexto. Por ello, cabe considerar que esta inserción supone una mayor lesividad para la víctima: de un lado, para su seguridad, con la disminución de las expectativas futuras de indemnidad, con el temor a ser de nuevo agredida; de otro, para su libertad, para la libre conformación de su voluntad, porque la consolidación de la discriminación agresiva del varón hacia la mujer en el ámbito de la pareja añade un efecto intimidatorio a la conducta, que restringe las posibilidades de actuación libre de la víctima; y además para su dignidad, en cuanto negadora de su igual condición de persona y en tanto que hace más perceptible ante la sociedad un menosprecio que la identifica con un grupo menospreciado. No resulta irrazonable entender, en suma, que en la agresión del varón hacia la mujer que es o fue su pareja se ve peculiarmente dañada la libertad de ésta; se ve intensificado su sometimiento a la voluntad del agresor y se ve peculiarmente dañada su dignidad, en cuanto persona agredida al amparo de una arraigada estructura desigualitaria que la considera como inferior, como ser con menores competencias, capacidades y derechos a los que cualquier persona merece.

No es el sexo en sí de los sujetos activo y pasivo lo que el legislador toma en consideración con efectos agravatorios, sino —una vez más importa resaltarlo- el carácter especialmente lesivo de ciertos hechos a partir del ámbito relacional en el que se producen y del significado objetivo que adquieren como manifestación de una grave y arraigada desigualdad. La sanción no se impone por razón del sexo del sujeto activo ni de la víctima ni por razones vinculadas a su propia biología. Se trata de la sanción mayor de hechos más graves, que el legislador considera razonablemente que lo son por constituir una manifestación específicamente lesiva de violencia y de desigualdad...»

La Sentencia 62/2008, de 26 de mayo, concluyó que el hecho de estar enfermo puede representar un factor de discriminación prohibido por la Constitución cuando esa circunstancia sea tomada en cuentan como un elemento de segregación basado en la mera existencia de la enfermedad o en la estigmatización como persona enferma de quien la padece, con independencia de que se ponga en relación dicha circunstancia con la aptitud del trabajador para desarrollar el contenido de la prestación laboral. En palabras del Tribunal:

«La situación de desventaja relativa de determinadas personas en el mercado de trabajo en razón de sus circunstancias físicas o de salud y su eventual riesgo de exclusión social constituyen problemas cuya atención corresponde a los poderes públicos, de conformidad con el artículo 9.2 CE, a través, entre otros, del con- 
junto de medidas de política sanitaria, de formación y readaptación profesionales y, en su caso, de protección social a las que se refieren los artículos 43.2, 40.2 y $41 \mathrm{CE}$, instrumentos esenciales para hacer realidad el modelo de «Estado social y democrático de Derecho» que nuestra Constitución impone (artículo 1.1 CE)».

La Sentencia 74/2008, de 23 de junio, concluyó que «la carga probatoria que recae sobre el empresario una vez que el trabajador ha aportado indicios de una conducta discriminatoria opera igualmente en los supuestos de decisiones discrecionales, o no causales, y que no precisan por tanto ser motivadas, pues ello no excluye que, desde la perspectiva constitucional, sea igualmente ilícita una decisión discrecional contraria a los derechos fundamentales del trabajador...

no cabe entender que, en el presente caso, el hecho de que el contrato se extinguiera a la llegada de su término resulte suficiente para neutralizar el indicio probatorio aportado por la trabajadora al proceso. Siendo ésta la única razón aducida por el Ayuntamiento para justificar su decisión, habremos de concluir que éste no ha acreditado la existencia de causa fundada y real que permita destruir la apariencia discriminatoria creada y alcanzar la necesaria convicción de que su decisión fue ajena a todo propósito atentatorio del derecho fundamental, al no tener por causa el estado de embarazo de la recurrente..., esta ausencia de prueba trasciende el ámbito puramente procesal y determina, en último término, que los indicios aportados por la demandante desplieguen toda su operatividad para declarar la lesión del derecho garantizado en el artículo 14 CE».

La Sentencia 92/2008, de 21 de julio, apreció discriminación por razón de sexo en el despido de una trabajadora embarazada sin que constase que el empresario conocía su estado ni se hubiese comunicado el embarazo. Considera el Tribunal que

"para ponderar las exigencias que el artículo 14 CE despliega en orden a hacer efectiva la igualdad de las mujeres en el mercado de trabajo es preciso atender a circunstancias tales como la peculiar incidencia que respecto de la situación laboral de aquéllas tiene el hecho de la maternidad, y la lactancia, en cuanto se trata de compensar las desventajas reales que para la conservación de su empleo soporta la mujer a diferencia del hombre. De hecho, el riesgo de pérdida del empleo como consecuencia de la maternidad de las mujeres trabajadoras constituye probablemente el problema más importante — junto a la desigualdad retributiva- con el que se enfrenta la efectividad del principio de no discriminación por razón de sexo en el ámbito de las relaciones laborales, problema de cuya trascendencia y gravedad dan cuenta los datos revelados por las estadísticas (referidos al número de mujeres que se ven obligadas a dejar el trabajo por esta circunstancia, a diferencia de los varones) e, incluso, la propia reiteración con que problemas de esta naturaleza han debido de ser abordados por la jurisprudencia 
de este Tribunal. Invariablemente, como antes recordábamos, el Tribunal ha declarado que un despido motivado por el embarazo de la trabajadora debe considerarse nulo, por discriminatorio, lo que en la regulación legal precedente a la que ahora se analiza recibió cobertura mediante la declaración como nulos en el artículo 55.5 LET de los despidos que tuvieran por móvil alguna de las causas de discriminación prohibidas en la Constitución o en la Ley, o que se produjeran con violación de derechos fundamentales y libertades públicas del trabajador. En aplicación de la doctrina de la prueba indiciaria establecida por este Tribunal, los Tribunales de Justicia y este Tribunal Constitucional en amparo han venido declarando la nulidad de aquellos despidos en los que, tras haberse aportado por la trabajadora un indicio razonable de vulneración de su derecho fundamental, no se hubiera acreditado por el empresario la existencia de una causa real suficiente y seria de extinción que acreditara que el despido era ajeno a un motivo discriminatorio, habiéndose exigido, para entender aportado por la trabajadora el referido panorama indiciario, que se acreditara el conocimiento por la empresa del estado de embarazo, pues, como anteriormente señalábamos, difícilmente puede considerarse que posee un móvil discriminatorio aquel despido en el que quien despide desconoce la concurrencia del factor de diferenciación en que consiste la discriminación. Pues bien, es sobre este panorama legislativo y jurisprudencial consolidado sobre el que actuó la reforma del legislador de la Ley 39/1999, denominada «de conciliación de la vida familiar y laboral de las personas trabajadoras». Y lo hizo, añadiendo al supuesto de nulidad ya contemplado en el artículo 55.5 LET para el caso de despidos discriminatorios o con vulneración de derechos fundamentales, un nuevo supuesto que, en lo que aquí interesa, declara también la nulidad ("será también nulo» dice la Ley) del despido de las trabajadoras embarazadas, desde la fecha de inicio del embarazo hasta la del comienzo del período de suspensión, salvo que se declare la procedencia del despido por motivos no relacionados con el embarazo. Y lo hace sin contemplar requisito específico alguno ni de comunicación previa del embarazo al empresario (a diferencia de lo que contempla la Directiva comunitaria), ni de conocimiento previo por parte de éste, por cualquier otra vía, del hecho del embarazo...

Frente a esta claridad interpretativa no puede oponerse el hecho de que la Directiva comunitaria prevea expresamente la necesidad de comunicación del estado de embarazo; antes al contrario, es manifiesto el apartamiento por el legislador nacional del texto de la Directiva en este aspecto concreto, cuya transposición omite íntegramente, advirtiéndose en la propia exposición de motivos que la transposición se efectúa «superando los niveles mínimos de protección» previstos en la Directiva... Exonerar de esta prueba del conocimiento del embarazo y, con ella, de toda obligación de declaración previa, sustituyéndola por la prueba en caso de despido de un hecho físico objetivo como es el embarazo en sí, constituye, sin duda, una medida de fortalecimiento de las garantías frente al despido de 
la trabajadora embarazada, al tiempo que plenamente coherente con el reconocimiento de su derecho a la intimidad personal y familiar (artículo 18.1 CE)... La garantía frente al despido del derecho a la no discriminación por razón de sexo de las trabajadoras embarazadas no exige necesariamente un sistema de tutela objetiva como el previsto por el legislador en la Ley 39/1999... Sin embargo, una vez que el legislador ha optado por un desarrollo concreto del artículo $14 \mathrm{CE}$, que incrementa las garantías precedentes conectándolas con una tutela también reforzada de otros derechos y bienes constitucionalmente protegidos, no puede el órgano judicial efectuar una interpretación restrictiva y ajena a las reglas hermenéuticas en vigor que prive al precepto legal de aquellas garantías establecidas por el legislador y con las que la trabajadora podía razonablemente entenderse amparada en su determinación personal, pues con ello se estaría impidiendo la efectividad del derecho fundamental de acuerdo con su contenido previamente...»

La Sentencia 176/2008, de 22 de diciembre, declaró que la condición de transexual es no puede ser motivo de discriminación pues aunque no aparece expresamente mencionada en el artículo 14, es una circunstancia incluida en la cláusula "cualquier otra condición personal o social» a la que debe ser referida la interdicción de la discriminación, lo que ya fue reconocido hace años tanto por el Tribunal Europeo de Derechos Humanos como por el Tribunal de Justicia de las Comunidades Europeas. Recuerda el Tribunal que

«una decisión judicial o de otro poder público que suprima, suspenda o restringa los derechos del progenitor en relación con sus hijos menores, cuya ratio decidendi descanse de manera decisiva, expresa o implícitamente, en la orientación sexual de dicho progenitor supone una diferenciación discriminatoria proscrita por el artículo $14 \mathrm{CE}$, pues en ningún caso el mero dato de la orientación sexual o, más específicamente, de la disforia de género puede erigirse en justificación objetiva y razonable para dispensar un trato discriminatorio en perjuicio de ese progenitor en el marco de sus relaciones paternofiliales. Ello implica que resulte exigible que la resolución judicial (o, en su caso, administrativa) que en estos casos pueda acordar una supresión o limitación de derechos del progenitor transexual en relación con sus hijos menores, extreme, al formular su juicio de ponderación, y teniendo siempre presente el interés prevalente del menor, la justificación de la necesidad y proporcionalidad de las medidas restrictivas acordadas, de suerte que el escrutinio de la resolución permita descartar, sin sombra de duda alguna, que la orientación sexual o la disforia de género del progenitor haya sido el verdadero motivo de la decisión adoptada.»

En el derecho autonómico se aprobó, la Ley 3/2008 de 3 de julio de 2008 de modificación de la Ley 7/2007, de 4 de abril, para la igualdad entre mujeres 
y hombres, y de protección contra la violencia de género en la Región de Murcia (BORM n n $^{\circ}$ 65, de 17 de julio)

Respecto a la protección de la vida y la integridad física cabe mencionar, la Sentencia 22/2008, de 31 de enero, en la que confirma que los riesgos para la integridad físicas de los menores exigen una especial cautela, también para evitar que lleguen a producirse, pero la mera entrega a su padre, en cumplimiento de una decisión sobre su custodia, no supone riesgo palmario o indudable.

La Sentencia 34/2008, de 25 de febrero, reitera que la protección del derecho fundamental a la integridad coincide con la prohibición de torturas y malos tratos del artículo 3 del Convenio Europeo de Derechos Humanos, lo que implica la incorporación de la jurisprudencia del Tribunal Europeo de Derechos Humanos sobre la materia, incluido el deber de las autoridades estatales de investigar y, en su caso, castigar cualquier vulneración del derecho.

En relación con la libertad ideológica, la ya citada Sentencia 12/2008, de 29 de enero, descartó que este derecho resultara menoscabado por la reforma de la LOREG que prescribió la composición equilibrada de las candidaturas electorales. El artículo 44 bis no impide la existencia de partidos con una ideología contraria a la igualdad efectiva entre los ciudadanos de uno u otro sexo ni obliga a que los promotores de las candidaturas compartan la llamada democracia paritaria: lo único que impone es que cuando se pretenda defender esas tesis a través del ejercicio de los cargos representativos se haga en listas electorales compuestas por personas de uno y otro sexo. En definitiva, tanto las formaciones políticas como los ciudadanos individualmente considerados podrán defender y postular la reforma de lo establecido en la disposición legal vigente, en legítimo ejercicio de sus libertades ideológica y de expresión.

Sobre libertad personal y seguridad destacan las Sentencias 27/2008, de 11 de febrero, y 35 y 37/2008, estas últimas de 25 de febrero. La 27/2008 recuerda que

«el automatismo con que el órgano judicial ha aplicado la facultad legal establecida en el artículo 504.2 LECrim, asumiendo que el dictado de una Sentencia condenatoria lleva implícita la prolongación de la prisión provisional hasta la mitad de la pena impuesta, colisiona frontalmente con el carácter excepcional de la prisión provisional y con las exigencias de motivación específicas de una medida restrictiva de libertad tan drástica. Si bien la Sentencia condenatoria puede añadir solidez a la consideración de la concurrencia de indicios racionales de la comisión de un delito por una persona, es decir, consolida la imputación de un delito a persona determinada, que es el presupuesto habilitante para la adopción de la prisión provisional, no puede desconocerse que, mientras el recurso contra la Sentencia condenatoria no se haya resuelto, dicho pronunciamiento sobre la culpabilidad del procesado sigue siendo provisional, de modo 
que, precisamente por ello, para que el provisionalmente condenado pueda seguir estando en prisión una vez ha expirado el plazo inicial, es preciso adoptar una decisión judicial específica que debe ponderar la garantía de la libertad personal frente a la necesidad del mantenimiento de la situación de prisión provisional para alcanzar una finalidad constitucionalmente legítima: evitar la reiteración delictiva o alcanzar la realización de la justicia penal.»

Conforme a las otras dos sentencias, se reitera el criterio de que no se deben inadmitir las solicitudes de habeas corpus sin haber oído personalmente al detenido. En el mismo sentido se pronunciaron las SSTC 172/2008, de 18 de diciembre, y 173/2008, de 22 de diciembre, respecto a inmigrantes interceptados en pateras cuando intentaban entrar en España.

La Sentencia 43/2008, de 10 de marzo, recuerda que la redención de penas de acuerdo con el derogado Código Penal de 1973 afecta al derecho fundamental a la libertad personal, ya que el periodo de privación de libertad depende, entre otros factores, de su aplicación conforme a la ley, en relación con la orientación reeducadora de la pena privativa de libertad (artículo 25.2).

La Sentencia 57/2008, de 28 de abril, también apreció vulneración del derecho del artículo 17 por la denegación a abonar en la liquidación de condena el tiempo en el que el reo estuvo privado provisionalmente de libertad en la causa al coincidir con el tiempo en que el reo se encontraba privado de libertad como penado, en cumplimiento de la condena impuesta en otra causa distinta. Textualmente:

«la situación de coincidencia entre la prisión provisional en una causa y la situación de penado en otra, por su frecuencia en la realidad, no es un supuesto que, lógicamente, pudiera haber pasado inadvertido al legislador, al regular el abono del tiempo de privación de libertad sufrido provisionalmente para el cumplimiento de la pena o pena impuestas en la misma causa (artículo 58.1 CP), lo que «desde la obligada pauta de la interpretación en el sentido de la mayor efectividad del derecho fundamental y de la correlativa interpretación restrictiva de sus límites» permite entender que, si el legislador no incluyó ninguna previsión respecto a dicha situación en el artículo 58.1 CP, y, en concreto, el no abono del tiempo en el que simultáneamente han coincidido las situaciones de prisión provisional en una causa y de penado en otra, fue sencillamente porque no quiso hacerlo. En todo caso, y al margen de problemáticas presunciones sobre la intención del legislador, el dato negativo de la no previsión de esa situación es indudable; y, a partir de él, no resulta constitucionalmente adecuada una interpretación en virtud de la cual pueda llegarse a una consecuencia sobre el abono del tiempo de prisión provisional en una causa para el cumplimiento de la pena o penas impuestas en la misma, regulado en el artículo 58.1 CP, basada en un dato ausente de éste.» 
En las Comunidades Autónomas se aprobaron varias normas legales: la Ley 2/2008, de 11 de abril, de modificación de la Ley 10/1994, de 11 de julio, de la Policía de la Generalidad-Mossos d'Esquadra (DOGC n ${ }^{\circ}$ 5114, de 18 de abril; $\mathrm{BOE} \mathrm{n}^{\circ} 117$, de 14 de mayo); la Ley 2/2008, de 28 de mayo, de tercera modificación de la Ley de Policía del País Vasco (BOPV no 112, Fascículo 1, de 13 de junio) y la Ley 7/2008, de 5 de junio, por la cual se modifica la Ley 6/2005, de 3 de junio, de coordinación de las policías locales de las Illes Balears (BOB n ${ }^{\circ}$ 81, Fascículo 1, de 10 de junio; BOE no 160 , de 3 de julio).

En lo que respecta al derecho al honor y su relación con el derecho a la producción y creación literaria, la STC 51/2008, de 14 de abril, señala que este último "protege la creación de un universo de ficción que puede tomar datos de la realidad como puntos de referencia, sin que resulte posible acudir a criterios de veracidad o de instrumentalidad para limitar una labor creativa y, por lo tanto, subjetiva como es la literaria. Por otro lado,... el párrafo litigioso, a pesar de identificar claramente a la persona pretendidamente ofendida, no puede considerarse lesivo de su honor, teniendo en cuenta su fallecimiento once años antes, que no nos encontramos ante un supuesto de sucesión procesal, y que, interpretado en su conjunto y en el contexto de una obra literaria que pretende describir la evolución de una determinada generación, el fragmento litigioso y, concretamente, las frases aparentemente vulneradoras de dicho honor no pueden considerarse ni en sí mismas vejatorias ni desmerecedoras de la reputación o consideración ajenas».

En relación con los derechos del artículo 20 y su ejercicio en el ámbito laboral, la Sentencia 56/2008, de 14 de abril, destacó que en la actualidad la actividad profesional posee una faceta externa, de relación social que, en cuanto tal, repercute en la imagen que de la persona tengan los demás. Algo similar podría sostenerse de la imagen de los representantes de los trabajadores en sus representados. Por ello, concluye que la protección del artículo 18.1 CE sólo alcanzaría a aquellas críticas que, pese a estar formalmente dirigidas a la actividad representativa de los miembros del comité de empresa y a los representantes de los trabajadores en general, constituyan en el fondo una descalificación personal, al repercutir directamente en su consideración y dignidad individuales, poseyendo un especial relieve aquellas infamias que pongan en duda o menosprecien su probidad o su ética en el desempeño de su función de representación; lo que, obviamente, dependerá de las circunstancias del caso, de quién, cómo, cuándo y de qué forma se ha cuestionado la valía del ofendido.

En el ámbito legislativo autonómico se aprobó la Ley 1/2008 de 11 de abril de 2008, de tercera modificación de la Ley del Principado de Asturias 2/2003, de 17 de marzo de Medios de Comunicación Social (BOPA n ${ }^{\circ}$ 96, de 25 de abril; $\mathrm{BOE} \mathrm{n}^{\circ} 149$, de 20 de junio). 
A propósito del derecho de reunión y manifestación, la STC 71/2008, de 23 de junio, concluyó que en el caso de internos en centros penitenciarios no opera sin más el artículo 21, en cuanto exime de autorización previa de la Administración para reunirse pacíficamente, sino que debe tenerse en cuenta el artículo 25.2 CE. De acuerdo con el Tribunal,

«el ejercicio del derecho de reunión en el interior de las prisiones puede quedar limitado por razones de orden y de seguridad constitucionalmente legítimas. A partir de ello, no cabe admitir la afirmación del recurrente de que las reuniones y concentraciones realizadas por internos dentro de centros penitenciarios no requieren de autorización previa, toda vez que no puede privarse a la Administración penitenciaria de que determine y pondere en cada caso si el pretendido ejercicio de este derecho resulta compatible con la condición de presos en general, con el cumplimiento de su pena privativa de libertad, con la seguridad y buen orden del establecimiento, con la libertad de los demás presos con los que obligadamente conviven los peticionarios y con la correcta prestación por los funcionarios del centro penitenciario de sus restantes servicios y funciones».

Por su parte, la STC 170/2008, de 15 de diciembre, declaró que este derecho no puede ser coartado por el mero hecho de que se pretenda ejercer en período electoral:

«el principio del pluralismo político se encuentra fuertemente vinculado con el derecho de libertad de expresión del que, como ya hemos puesto de relieve, es manifestación colectiva el derecho de reunión, siendo éste, al igual que la mencionada libertad, un derecho que coadyuva a la formación y existencia «de una institución política, que es la opinión pública, indisolublemente ligada con el pluralismo político» (STC 12/1982, de 31 de marzo , FJ 3), de forma tal que se convierte en una condición previa y necesaria para el ejercicio de otros derechos inherentes al funcionamiento de un sistema democrático, como lo son precisamente los derechos de participación política de los ciudadanos... No puede admitirse, por tanto, que la manifestación convocada por el Colectivo Autónomo de Trabajadores-Mossos d'Esquadra (CAT-ME) se prohíba por su "posible» incidencia en el proceso electoral. Y ello no sólo por las dudas que hace explícitas la propia Junta Electoral Provincial de Barcelona en su acuerdo, al utilizar la expresión «al poder tenir incidència sobre el procés electoral», sino porque en sí es dudoso que tenga capacidad suficiente para influir en las decisiones de los electores. Pues bien en tales circunstancias, debe favorecerse el ejercicio del derecho de reunión aún en detrimento de otros derechos, en especial los de participación política, no sólo por significarse como un derecho esencial en la conformación de la opinión pública, sino por la necesidad de su previo ejercicio para una configuración de la misma libre y sólida, base indispensable para el ejercicio de los mencionados derechos. Por este motivo, el ejercicio del derecho de reunión, del 
que el derecho de manifestación resulta una vertiente, debe prevalecer, salvo que resulte suficientemente acreditado por la Administración y, en su caso, por los Tribunales, que la finalidad principal de la convocatoria es la captación de sufragios.»

En materia de tutela judicial deben recordarse la Ley Orgánica 2/2008, de 4 de diciembre, de modificación de la Ley Orgánica 6/1985, de 1 de julio, del Poder Judicial, complementaria de la Ley para la ejecución en la Unión Europea de Resoluciones que impongan sanciones pecuniarias (BOE núm. 293, de 5 de diciembre de 2008) y la Ley $1 / 2008$, de 4 de diciembre, para la ejecución en la Unión Europea de resoluciones que impongan sanciones pecuniarias (BOE núm. 293, de 5 de diciembre de 2008).

No pueden obviarse las ya citadas condenas a España por parte del Tribunal Europeo de Derechos Humanos por vulneración de derechos conectados con el que nos ocupa: en el caso Barrenechea c. España, la sentencia de 22 de julio estimó que se había producido la vulneración del artículo 6 del Convenio Europeo de Derechos Humanos en un supuesto en el que el Tribunal Supremo admitió inicialmente un recurso de casación pero, cinco años después, lo inadmitió por sentencia sin responder a las alegaciones relativas a los eventuales motivos de inadmisibilidad apreciados. En la misma fecha se dictó la sentencia del caso Gómez de Liaño c. España, en la que se apreció, por unanimidad, la violación del derecho a un tribunal imparcial al considerar que el Tribunal que debía juzgar al demandante por prevaricación ofrecía dudas de imparcialidad, pues todos sus miembros habían intervenido en numerosos actos de instrucción y, en particular, en la apelación contra el Auto de procesamiento dictado contra el demandante.

En cuanto a las numerosas sentencias del Tribunal Constitucional que se han pronunciado sobre alguno de los derechos protegidos por el artículo 24 de la Constitución, mencionaremos únicamente algunas de las que consideramos más novedosas o significativas:

Varias sentencias (SSTC 3/2008, de 21 de enero; 72/2008, de 23 de junio; 106/2008, de 15 de septiembre; 171/2008, de 15 de diciembre, y 175/2008, de 22 de diciembre) anulan la inadmisión de demandas dirigidas contra Administraciones que no habían resuelto las solicitudes o los recursos formulados por los ciudadanos, reiterando que la falta de impugnación del silencio de las Administraciones públicas no equivale al consentimiento del administrado y que la inactividad de las autoridades incumple la legislación administrativa y nunca debe colocarlas en mejor situación que si hubieran cumplido con su deber de dictar y notificar la correspondiente resolución expresa.

La Sentencia 8/2008, de 21 de enero, reitera que debe permitirse la personación de la Administración como acusadora en casos de violencia doméstica si 
estaba prevista por una Ley de la Comunidad Autónoma, de prevención de la violencia contra las mujeres y la protección a sus víctimas.

La Sentencia 40/2008, de 10 de marzo, recuerda que la presunción de inocencia rige sin excepciones en el ordenamiento sancionador y ha de ser respetada en la imposición de cualesquiera sanciones, penales o administrativas. Si la Administración impone una sanción recae sobre ella la carga probatoria tanto de la comisión del ilícito como de la participación del acusado, sin que a éste pueda exigírsele una probatio diabolica de los hechos negativos.

La Sentencia 60/2008, de 26 de mayo, reafirma que el principio acusatorio incluye entre sus garantías la de que nadie puede ser condenado por cosa distinta de la que se le ha acusado y de la que haya podido defenderse, y que esa garantía debe ser respetada tanto en el juicio como en los eventuales recursos que pudieran interponerse.

La Sentencia 93/2008, en un recurso sobre la denegación de una autorización de residencia y trabajo, declara vulnerado el derecho pues las causas estructurales y la excesiva carga de asuntos no justifican las dilaciones.

La Sentencia 125/2008, de 10 de octubre, otorgó el amparo a una trabajadora despedida después de haber acudido a los Tribunales para la defensa de sus derechos laborales: el despido es nulo porque la empresa no probó que su causa fuera distinta al hecho de haberla demandado.

En materia de legalidad sancionadora, la Sentencia 113/2008, de 29 de septiembre, reitera que las ordenanzas municipales no son normas que puedan establecer infracciones administrativas o sanciones, pero la necesaria cobertura legal no es tan intensa como la aplicable a los reglamentos ejecutivos, pues los Plenos municipales son entidades representativas. Por ello desestimó el amparo planteado por el titular de un vehículo multado por aparcamiento indebido pues la infracción y la sanción estaban previstas en la ordenanza municipal, amparada a su vez en la Ley de Tráfico y Seguridad Vial.

Sí se otorgó el amparo en la Sentencia 181/2008, de 29 de diciembre (médico sancionado por una infracción grave de intrusismo profesional) porque las normas con rango de ley aplicadas no definían la infracción y la Constitución no permite integrar una norma sancionadora en blanco mediante una remisión normativa en cadena a otras normas de rango inferior o incluso a meras resoluciones y planes de estudio.

Sobre el derecho a la educación, hay que mencionar la Ley 3/2008, de 13 de junio de 2008, de segunda modificación de la Ley de la Escuela Pública Vasca (BOPV no 118, Fascículo 1, de 23 de junio).

Por lo que respecta a la libertad sindical, la STC 90/2008, de 21 de julio, recuerda que el Tribunal ha tenido ya la oportunidad de reaccionar frente a decisiones de las Administraciones adoptadas en perjuicio de la situación profesional 
de los representantes sindicales y fundadas en la adquisición por éstos de la condición de liberado sindical, no dudando en tacharlas de lesivas del derecho de libertad sindical y también ha otorgado amparo constitucional a representantes de los trabajadores, liberados sindicales, en supuestos en los que, al margen de cualquier motivación antisindical, concurrían perjuicios en sus condiciones económicas derivados concretamente de la falta de prestación de servicios profesionales que era consustancial a su condición de representante de los trabajadores en situación de liberado por razón sindical.

La STC 137/2008, de 27 de octubre, reiteró que comprende el derecho del trabajador a no sufrir, por razón de su afiliación o actividad sindical, menoscabo alguno en su situación profesional o económica en la empresa. Si no se permite alegar como mérito en el concurso de promoción interna el tiempo dedicado a realizar funciones representativas se está obligando, de manera indirecta, a escoger entre su carrera y la actividad sindical. Esta es la primera sentecia dictada por una Sección que otorga un amparo.

Por su parte, la Sentencia 152/2008, de 17 de noviembre, sostuvo que es irrelevante que se hable de asociación o sindicato; lo importante es que las personas se agrupen para llevar a cabo colectivamente la defensa de los intereses profesionales que les son comunes, lo que viene definido en sus estatutos. Tampoco importa para ser titular del derecho la cualificación profesional de los funcionarios asociados, a los que se había calificado como «cuerpos de élite».

En cuestiones tributarias han de citarse la Ley 4/2008, de 23 de diciembre, por la que se suprime el gravamen del Impuesto sobre el Patrimonio, se generaliza el sistema de devolución mensual en el Impuesto sobre el Valor Añadido, y se introducen otras modificaciones en la normativa tributaria (BOE núm. 310, de 25 de diciembre de 2008) y la Ley 1/2008, de 16 de abril de 2008, de la Presidencia del Gobierno de modificación de la Ley 9/2006, de 11 de diciembre, Tributaria de la Comunidad Autónoma de Canarias (BOCa n ${ }^{\circ} 81$, de 22 de abril, y $\mathrm{BOE} \mathrm{n}^{\circ} 113$, de 9 de mayo).

En cuanto al derecho de propiedad, se aprobó la Ley 3/2008, de 23 de diciembre, relativa al derecho de participación en beneficio del autor de una obra de arte original (BOE núm. 310, de 25 de diciembre de 2008).

En materia de fundaciones, cabe citar la Ley 9/2008, de 3 de julio, de modificación de la Ley 8/1998, de 9 de diciembre, de Fundaciones de la Comunitat Valenciana (DOGV n ${ }^{\circ} 5803$, de 10 de julio; Corrección de errores: DOGV $\mathrm{n}^{\circ} 5809$, de 18 de julio; BOE ${ }^{\circ} 192$, de 9 de agosto).

Sobre derechos sociales en general hay que mencionar, en el País Vasco, la Ley 8/2008, de 25 de junio, por la que se modifica la Ley contra la Exclusión Social y la Ley de Carta de Derechos Sociales (BOPV nº 127, Fascículo 1, de 4 de ju- 
lio) y, en Navarra, la Ley Foral 13/2008, de 2 de julio, de 2008 de modificación de la Ley Foral 9/1999, de 6 de abril, para una Carta de Derechos Sociales (BON no 87, Fascículo 1, de 16 de julio; BOE no 199, de 18 de agosto).

En cuanto a la protección de la salud, se aprobaron la Ley Foral 10/2008, de 30 de mayo, por la que se modifica el artículo 5 de la Ley Foral 10/1990, de 23 de noviembre, de Salud (BON n ${ }^{\circ} 70$, de 6 de junio; BOE no 173, de 18 de julio) y la Ley Foral 20/2008, de 20 de diciembre, por la que se modifica la Ley Foral 12/2000, de 16 de noviembre, de Atención Farmacéutica (BON n ${ }^{\circ}$ 146, de 1 de diciembre; $\mathrm{BOE} \mathrm{n}^{\circ} 309$, de 24 de diciembre).

En materia de protección medioambiental cabe citar varias leyes autonómicas: en Cataluña, la Ley 9/2008, de 10 de julio, de modificación de la Ley 6/1993, de 15 de julio, reguladora de los residuos (DOGC no 5175, de 17 de julio; BOE $\mathrm{n}^{\circ}$ 190, de 7 de agosto); en Castilla y León, la Ley 9/2008, de 9 de diciembre, de modificación de la Ley 6/1992, de 18 de diciembre, de protección de los ecosistemas acuáticos y de regulación de la pesca en Castilla y León (BOCL n ${ }^{\circ} 249$, de 26 de diciembre; BOE n ${ }^{\circ}$ 15, de 17 de enero de 2009); y en Aragón, la Ley 8/2008, de 23 de diciembre, de modificación de la Ley 2/1992, de 13 de marzo, de creación del Consejo de Protección de la Naturaleza (BOA n ${ }^{\circ} 222$, de 31 de diciembre; $\mathrm{BOE} \mathrm{n}^{\circ} 26$, de 30 de enero de 2009).

En cuanto a las políticas de vivienda, deben recordarse la Ley 1/2008, de 4 de abril, por la que se establecen medidas urgentes para la adaptación del ordenamiento urbanístico a la Ley 8/2007, de 28 de mayo, de suelo, garantías de sostenibilidad del planeamiento urbanístico e impulso a las políticas activas de vivienda y suelo en la Comunidad Autónoma de Aragón (BOA n ${ }^{\circ} 40$, de 7 de abril; BOE no 116, de 13 de mayo) y la Ley 4/2008, de 10 de octubre, de adaptación del Instituto de Vivienda y Suelo de la Región de Murcia a la Ley 7/2004, de 28 de diciembre, de Organización y Régimen Jurídico de la Administración Pública de la Comunidad Autónoma de la Región de Murcia (BORM n ${ }^{\circ} 249$, de 25 de octubre).

Finalmente, para la protección de los consumidores, entró en vigor la Ley 1/2008, de 21 de abril, por la que se modifica la Ley 4/1996, de 14 de junio, del Estatuto de los Consumidores y Usuarios de la Región de Murcia (BORM n ${ }^{\circ}$ 120 , de 24 de mayo). 